\title{
Termomagnetismo ou termoeletricidade? Um estudo do trabalho de Thomas
} Johan Seebeck ${ }^{+*}$

Éwerton Jefferson Barbosa Ferreiral

Licenciando em Física - Universidade Estadual da Paraíba

Ana Paula Bispo Silva ${ }^{2}$

Departamento de Física - Universidade Estadual da Paraíba

Campina Grande - PB

\section{Resumo}

O efeito Seebeck é aquele presente nos termopares para medição de temperaturas a longas distâncias. Ele envolve a relação entre a eletricidade e a diferença de temperatura entre dois metais. Neste trabalho apresentamos a análise e tradução de partes do trabalho de Thomas Johan Seebeck em que o fenômeno é estudado. A análise mostrou que há diferenças consideráveis entre o trabalho original e o efeito como entendemos hoje.

Palavras-chave: Thomas Johan Seebeck; Termomagnetismo; Termoeletricidade.

\begin{abstract}
Seebeck effect is present in thermocouples to measure temperature to distance. It is based on the relation between electricity and a difference of temperature in a combination of metals. In this work, we present the analysis and translation of parts of the original work of Thomas Johan Seebeck which discuss the phenomena. The analysis reveals that there are many differences between the original meaning and what we understand nowadays about Seebeck effect.
\end{abstract}

\footnotetext{
${ }^{+}$Thermomagnetism or thermoelectricity? A study of Thomas Johan Seebeck's work

* Recebido: abril de 2016.

Aceito: julho de 2016.

1 E-mail: ewertonjeferson@hotmail.com

2 E-mail: anabispouepb@gmail.com
} 
Keywords: Thomas Johan Seebeck; Thermagnetism; Thermoelectricty.

\section{Introdução}

Durante século XIX, quando a eletricidade e o magnetismo ocupavam a cena central da ciência, experimentos mostravam cada vez mais a necessidade de unificação da física, com teorias que se aplicavam em todas as áreas. Por outro lado, as novas descobertas levaram a um avanço tecnológico, com a invenção de novos equipamentos e, consequentemente, novas observações.

Dentre as novas observações, este trabalho apresentará um estudo de caso sobre os estudos de Seebeck (MAGIE, p. 461, 1935). Em 1821, Seebeck relatou a observação de efeitos magnéticos ao estabelecer uma diferença de temperatura entre dois metais. Nos anos posteriores, o "efeito Seebeck", como ficou conhecido por demonstrar a termoeletricidade, levou à criação de aparelhos de detecção de temperaturas a partir de diferenças de voltagem (termopar) e após certo tempo, na criação de equipamentos para medir temperaturas à longa distância (ROGALSKI, 2002). No entanto, apesar do avanço que permitiu em diversas áreas, o estudo histórico deste episódio da ciência é pouco explorado.

Neste trabalho apresentamos um pouco da biografia de Seebeck, as influências que pode ter recebido, fazemos uma análise dos experimentos que ele fez e trazemos a tradução dos principais trechos que permitem compreender suas ideias.

\section{Biografia de Thomas Johann Seebeck $(1770-1831)^{3}$}

Thomas Johann Seebeck nasceu em 9 de Abril de 1770, na cidade de Reval (atual Tallin, capital da Estônia). Seu pai se chamava Johann Christoph Seebeck, um comerciante, e sua mãe Gerdrutha Lohmann, que era filha de um comerciante.

Após a morte do pai em 1786, como anos antes sua mãe já havia morrido, Seebeck juntamente com seu irmão Christoph ficaram sob tutela da avó Anna Gerdrutha Seebeck e de sua tia Catharina Margaretha Wilcke. Passados 10 anos da morte do pai, 1796, Christoph, irmão de Seebeck, morre, sendo assim Seebeck passa a ser o herdeiro legítimo dos bens de seu pai.

Seebeck não seguiu os negócios da família - o ramo do comércio - mas sim trilhou uma carreira acadêmica. Graduou-se em 1788 pela Reval Imperial Grammar School e seguiu seus estudos em medicina viajando para Berlim e posteriormente para a Universidade de Göttingen, sendo aprovado com excelência nos exames em 1792. Apesar de sua formação como médico ele não exerceu a medicina, empreendendo estudos em física, fato este que foi proporcionado pela herança de seu pai.

No ano de 1795 Seebeck casou-se com Juliane Amalie Ulrike Boye, em Bayreuth, onde havia se estabelecido. No verão de 1802 Seebeck viajou com sua família para Jena, onde

\footnotetext{
${ }^{3}$ Os dados biográficos foram baseados fundamentalmente em Velmre (2007).
} 
estavam presentes filósofos naturais e intelectuais, como por exemplo Schelling e Oken, principais expoentes da Naturphilosophie, com os quais mantinha relações. Neste período Seebeck fez amizade com Hegel e Goethe. Estas amizades influenciaram o trabalho de Seebeck, uma vez que a Naturphilosophie pressupunha um comportamento para a natureza que envolvia as diversas forças em estudo no período, como calor, eletricidade e magnetismo (CANEVA, 1997).

Em 1818 foi eleito como membro correspondente da Academia de Ciências da Prússia (Berlim). Ao mudar-se para Berlim em janeiro de 1819, Seebeck passou a ser membro efetivo desta Academia.

Seebeck até então empreendia estudos sobre óptica, porém com o conhecimento do trabalho de Hans Christian Oersted (1777-1851) sobre eletromagnetismo, mudou o rumo de suas pesquisas. Esta recém descoberta fez com que ele optasse pelo desenvolvimento de estudos em eletricidade e magnetismo. Os frutos desta sua escolha foram colhidos cedo, pois em 16 de Agosto de 1821 Seebeck reporta a Academia de Berlim o "termomagnetismo" de um circuito galvânico.

Em 1823 Seebeck já estava apresentando dificuldades quanto à sua saúde, falecendo em 10 de Dezembro de 1831, em Berlim, deixando 6 filhos e 2 filhas.

\section{Análise do trabalho de Seebeck}

Ainda que de maneira resumida, cabe-nos aqui apresentar um pouco sobre o que estava em destaque nos estudos sobre eletricidade e magnetismo quando Seebeck realizou seus experimentos. Na década de 1820, os trabalhos de Luigi Galvani (1737-1798) e Alessandro Volta (1745-1827) já eram bem conhecidos e a pilha, uma fonte de eletricidade, passou a ter papel principal no desenvolvimento de novos estudos. Mas, se por um lado a invenção de equipamentos que usavam a pilha estava em largo avanço, por outro, o conhecimento da natureza da eletricidade ainda permanecia uma incógnita. O mesmo ocorria com o magnetismo, do qual se conhecia as propriedades, mas não a natureza.

Já se sabia também que havia uma relação entre eletricidade e magnetismo, como o fato de bússolas serem afetadas em tempestades e Hans Christian Oersted já havia publicado um trabalho (em 1812) em que discutia as relações entre os dois fenômenos (OERSTED, 1813, p. 6; MARTINS, 1986)

Além das observações sistemáticas de fenômenos, buscando relacionar a eletricidade e o magnetismo, alguns dos principais estudiosos do assunto, como Johann Wilhelm Ritter (1776-1810) e Oersted também realizavam estudos sobre a Naturphilosophie. A Naturphilosophie é uma corrente filosófica que tem suas origens no Romatismo alemão e tinha como uma de suas teses a defesa da unificação das forças da natureza. Sob influência da Naturphilosophie, 
era natural para os envolvidos nela pensar em opostos, polaridades, unificações e, consequentemente, aceitar a relação entre as duas "forças" eletricidade e magnetismo 4 (CANEVA, 1997; CANEVA 2001; MAGALHÃES, 2005).

Seebeck também fazia parte dos estudiosos que estavam sob influência da Naturphilosophie. Acresce-se a isso o fato de que, em 1820, Oersted já havia divulgado seu trabalho sobre o efeito que correntes elétricas produziam sobre bússolas. Portanto, este cenário era favorável para que ele fizesse os experimentos que fez.

No entanto, da forma como Seebeck apresenta seu trabalho, a relação entre a diferença de temperatura dos metais e a mudança na orientação da bússola, não envolvia diretamente a eletricidade. Estava mais relacionada com outra "força" da natureza, o calor, que levava à produção de efeitos magnéticos.

No trabalho traduzido aqui, Seebeck investiga o fato observado de que a diferença das ações, seja ela variação de temperatura, pressão, superposição de outros materiais, etc. na junção de dois metais ligados em circuito, produz uma polarização magnética sem o auxílio de um condutor líquido - uma bateria (SEEBECK, 1895). Inicialmente ele realiza experimentos estudando o efeito que diferentes metais poderiam produzir sobre bússolas, observando ou não a declinação da agulha em algumas situações. Ele elabora vários experimentos consistindo na junção de diferentes metais em circuito fechado - ex.: em arco, espirais ou anéis - e aquecendoos em uma das junções, em que para verificar os efeitos utiliza uma agulha magnética, chegando a conclusão de que estes metais estabelecem uma série magnética (CANEVA, 2001). Em suas experiências, Seebeck utilizou diferentes tipos de metais e minérios, como cobre, zinco, bismuto, antimônio e etc. Na maioria dos arranjos ele utilizou cobre, bismuto e antimônio.

Ao realizar estes experimentos, ele acaba por conjecturar que talvez a temperatura do corpo utilizado para fechar o circuito é que fosse a causa da declinação da agulha, o que é afirmado no parágrafo 11 do texto. Uma nova série de experimentos em que a temperatura dos metais é variada, leva-o à conclusão de que uma condição necessária para o aparecimento do magnetismo, era a existência de uma diferença de temperatura nas junções dos dois metais interligados que constituíam o circuito.

Se a temperatura variasse de forma igual para os dois metais, então não ocorreria a flexão da agulha da bússola, porque, segundo Seebeck, isso provocaria polarizações opostas, anulando o efeito. Seebeck fornece uma possível explicação para o fenômeno (parágrafo 18), argumentando que o magnetismo aparece em qualquer caso em que há contato entre dois metais. Porém, ele permanece latente porque as forças, no contato, são iguais. Ao aumentar ou resfriar a temperatura de um dos metais, ocorre uma tensão magnética no circuito formado com os metais, quebrando o equilíbrio magnético (SEEBECK, 1895, p. 11).

\footnotetext{
${ }^{4}$ Não é o objetivo deste trabalho tratar de maneira aprofundada a Naturphilosophie e sua influência nos estudos sobre eletricidade e magnetismo. Para mais detalhes sobre esse tema sugerimos Caneva (1997; 2001) e Magalhães (2005).
} 
Realizando outros experimentos em que a diferença de temperatura ocorre sem o contato dos metais, Seebeck observa que não há flexão da agulha. Portanto, ele é levado a concluir (parágrafo 22) que a segunda condição necessária para o aparecimento do magnetismo é o contato entre os metais (SEEBECK,1895, p. 13). Todas as conclusões a que Seebeck chega levamno a afirmar que a diferença de temperatura desperta ou provoca uma mudança na agulha sob ação magnética. Ele não afirma nada sobre o surgimento de fenômenos elétricos. Assim, podese concluir que o fenômeno observado por Seebeck é de natureza térmica e magnética.

\section{Termoeletricidade ou termomagnetismo?}

Como já afirmamos, o século XIX foi um período de várias invenções. Muitas delas provenientes dos estudos de Alessandro Volta (1745-1827) e da pilha inventada por ele. A compreensão da eletricidade animal e a discordância com Galvani, também levaram Volta a identificar uma relação entre eletricidade e temperatura. A eletricidade animal foi a hipótese sugerida por Luigi Galvani (1737-1798) em 1791, ao observar a contração dos músculos das pernas de uma rã quando um condutor metálico era colocado em contato com os mesmos. Inicialmente Volta concordou com a ideia da eletricidade animal, mas posteriormente com o empreendimento de estudos mais detalhados sobre os trabalhos de Galvani concluiu que esta não era a causa das contrações musculares da rã, mas os metais em contato eram a causa principal (MARTINS, 2008).

Ao realizar experimentos ${ }^{5}$ para defender sua hipótese, Volta observa que ao mergulhar o metal e as pernas da rã em recipientes com água fervente e água fresca, havia uma produção diferente de fluido elétrico, como se a perna da rã funcionasse como outro metal (COMASCO, 1816, p. 203; ANATYSHUK, 2004). Como o efeito observado por Volta é explicitamente declarado por ele como afetando o fluido elétrico, podemos afirmar que, nesse caso, trata-se de um efeito de natureza térmica e elétrica.

É importante comentarmos, ainda que brevemente, a respeito da terminologia dos fenômenos observados por Seebeck. Ele mostrou seus estudos a Oersted que posteriormente sugeriu nomeá-los de circuitos termoelétricos. Outro pesquisador chamado Julius Conrad von Yelin tomou conhecimento dos trabalhos de Seebeck, através de Oersted, e ao desenvolver estudos próprios com relação a estes fenômenos sugeriu a terminologia de termoeletromagnéticos. Os aparatos de Yelin não constituíam um circuito fechado, mas apenas metais "soltos", como exemplo uma barra ou um disco. As questões terminológicas sobre os trabalhos de Seebeck perduraram até 1825 (CANEVA, 2001).

Sobre a prioridade em termoeletricidade é interessante notarmos que não podemos afirmar qual deles (Seebeck ou Volta) descobriu realmente a termoeletricidade, pois Seebeck em seus experimentos analisava a polarização magnética, de certa forma um efeito de natureza

\footnotetext{
${ }^{5}$ A descrição dos experimentos e seus resultados são apresentado por Volta em três cartas que ele envia para o abade Anton Maria Vassalli (Nuova memoria sull'eletricitáanimale divisa in tre lettere dirette al signor Abate Anton maria Vassalli), no período entre 1794 e 1795 (COMASCO, 1816, p. 195).
} 
magnética. Já Volta investiga outra coisa com seus experimentos utilizando os arcos metálicos com relação as contrações das rãs. Então seria um erro afirmar que algum destes estudiosos "descobriu a termoeletricidade" de fato, pois nenhum deles fala em tal coisa, no sentido que entendemos atualmente. No entanto, segundo Pastorino (2009), num workshop internacional realizado pela Academia Internacional de Termoeletricidade no município do Como em 14 de julho de 2005 foi fixada a prioridade de Alessandro Volta na descoberta deste fenômeno.

De acordo com Caneva (2001), a intenção de Seebeck não era uma investigação experimental de caráter termoelétrico, mas sim algo inteiramente diferente. Como nos diz Anatychuk (2004), sobre a caracterização das investigações experimentais destes cientistas tem-se que, enquanto Volta empreendeu estudos sobre as forças termoeletromotrizes geradas pela diferença de temperatura, Seebeck observou em seus estudos o fenômeno magnético excitado pelas correntes termoelétricas devido a diferença de temperatura.

Analisando as configurações dos experimentos realizados por Seebeck e considerando apenas a sua realização imediata que consiste em aquecer uma junção de dois metais interligados e como resultado disto observar uma deflexão da agulha em seu interior, certamente a justificativa deste fenômeno poderia ser a termoeletricidade. Entretanto, com uma leitura mais cuidadosa do trabalho de Seebeck percebe-se que seu trabalho tratava de um fenômeno totalmente diferente de termoeletricidade.

\section{A obra traduzida}

Este trabalho consiste na tradução e análise dos primeiros 24 parágrafos do "Magnetische Polarisation der Metalle und Erze durch Temperatur-Differenz" (Polarização Magnética de metais e minérios pela diferença de temperatura) de Thomas Johann Seebeck. A obra contém as observações do final de julho de 1821 e começo de fevereiro do ano de1822.

Para a tradução, além da obra original, também utilizamos a versão em inglês deste mesmo trabalho feita por Magie (1935), que fornece em sua transcrição apenas alguns dos parágrafos do trabalho original de Seebeck (1821-1822). A ampliação na tradução foi feita com a intenção de obter-se mais detalhes sobre os trabalhos de Seebeck. Ainda que incompleta, os parágrafos traduzidos e analisados contêm a ideia central dos experimentos de Seebeck. $\mathrm{Na}$ elaboração desta tradução teve-se muita cautela, analisando-se os termos utilizados por Magie (1935) como correspondentes aos utilizados por Seebeck, com o intuito de manter as ideias as mais coerentes possíveis.

Para uma melhor compreensão, dos trechos aqui traduzidos pelo autor, nossas ênfases estão entre chaves ' \{\} '. As notas do próprio Seebeck serão indicadas pelas iniciais N.A. (notas do autor) e as nossas N.T. (notas do tradutor). 
$[265]^{6}$ Polarização Magnética de metais e minérios pela diferença de temperatura do Sr. Seebeck

[Extraído de quatro palestras realizadas na Academia de Ciências em 16 de Agosto, 18 e 25 de Outubro e 11 de Fevereiro de 1822]

[266] Enquanto continuava minhas investigações sobre relações elétricas, químicas e magnéticas, que ocorrem mutuamente em baterias galvânicas, encontrei fenômenos que pareciam me mostrar que dois metais por eles mesmos, simplesmente juntos um com o outro em um circuito, podem tornar-se magnéticos sem a ação adicional de um condutor líquido. Outros motivos também pareciam a favor deste ponto de vista. Então, a partir de respectivos fatos, particularmente a partir daqueles já noticiados em artigo anterior ${ }^{7}$, parece seguir-se que a polarização magnética de todo o circuito fechado é determinada não apenas no ponto de contato dos metais uns com os outros, mas sim pela desigualdade das ações sobre os dois pontos de contato dos metais com o condutor úmido; também não se pode duvidar que, mesmo se a ação no primeiro ponto de contato nomeado seja reconhecida como contribuindo em parte para a excitação do magnetismo, certamente o excesso de ação em um dos pontos de contato mais do que em ambos os outros, poderia produzir uma tensão magnética; e isso acredito justificar as expectativas de que se houver alguma diferença das condições nos pontos de contato dos dois metais unidos em circuito, uma polarização magnética pode ocorrer.

Para a primeira pesquisa realizada deste ponto de vista, escolhi dois metais, bismuto e antimônio, para os quais encontrei muitos aspectos peculiares e variáveis quando são utilizados como elementos em conjunto com cobre na célula galvânica comum. Com ambos satisfiz minhas expectativas, ainda que suas ações sejam diferentes.

1. Uma placa de bismuto encontrando-se imediatamente sobre uma placa de cobre entre as duas extremidades de uma fita de cobre espiralada \{enrolada em espiral\} de 40 pés de comprimento e $2^{1 / 2}$ linhas $^{8}$ de largura e que se encontra no meridiano magnético, mostrou, quando o circuito está fechado, uma distinta divergência na agulha magnética ${ }^{9}$.

[267] A espiral estava para o norte e a suas extremidades \{fios a e b\} para o sul, assim como o polo norte $(-m)^{10}$ da agulha, que no interior da espiral ficou alguns graus a oeste, quando

\footnotetext{
${ }^{6}$ N.T. - Ao longo do texto original aparecem numerações entre colchetes que não conseguimos relacionar com números de páginas ou referências anteriores. Serão mantidas aqui para preservar a fidedignidade do texto original. ${ }^{7}$ N.T. - Aqui Seebeck está falando de um artigo seu de 1820-1821, no qual ele estuda o magnetismo das baterias galvânicas.

${ }^{8}$ N.T. - $\mathrm{O}$ valor de 1 linha de comprimento é equivalente à 0,25 centímetros e o de 1 pé de comprimento a aproximadamente 30,5 centímetros.

${ }^{9}$ N.T. - Magie (1935) utiliza 'placa' como tradução para o termo Scheibe (sig.-disco), contido no trabalho original de Seebeck. Então apenas por uma questão de conformidade também adotaremos o significado, pois no geral tal consideração não distorce a ênfase do trabalho de Seebeck.
}

${ }^{10}$ N.A. - O polo norte da Terra é designado por + M. 
a extremidade superior da espiral foi comprimida sobre a placa de bismuto (Fig. 1). Por outro lado, a declinação era leste, quando a espiral estava no Sul e a placa de metal no Norte.

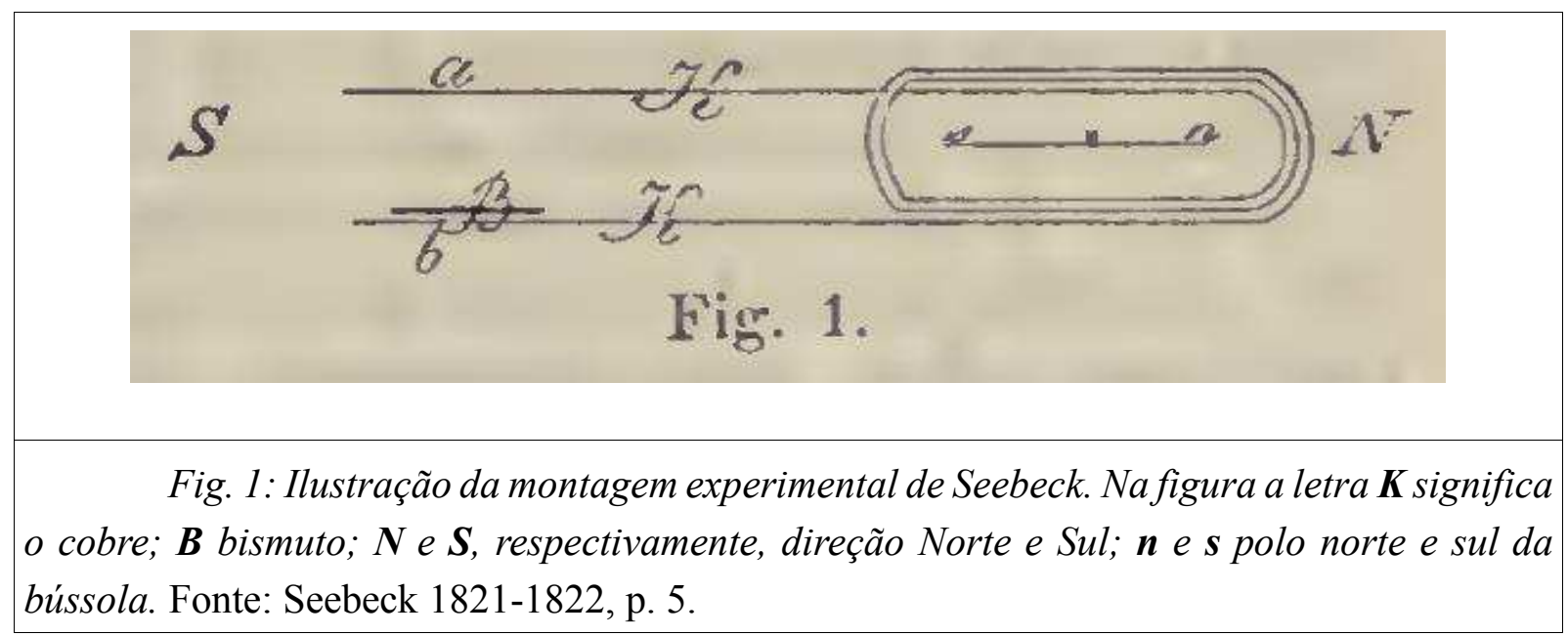

Quando a placa de bismuto foi colocada em cima da placa de cobre, de modo que a extremidade superior da espiral ficasse comprimida sobre a placa de cobre, a declinação \{da agulha da bússola\} permaneceu na mesma direção, sendo apenas mais fraca. Este resultado é determinado facilmente nas seguintes experiências, quando as placas metálicas simples apenas são colocadas em contato com a espiral, ou até mesmo outros metais, que se mostram de forma mais eficaz.

$\mathrm{Na}$ inversão da espiral, de maneira que a extremidade anteriormente localizada abaixo agora foi para cima, a declinação não muda, se a posição da espiral não for simultaneamente alterada. Daqui decorre que a causa de alguma tensão magnética do arranjo não se encontra na diferença da localização da extremidade da espiral.

Mesmo uma simples fita de folha de cobre, um arco batido em torno da bússola e trazido em contato com a placa de bismuto do tipo mencionada, deu a mesma declinação, embora mais fraca do que no caso da espiral. A declinação nesta \{espiral $\}$ estava fixa em $7^{\circ}$, para uma fita de cobre de $1 / 2$ polegada de largura deu uma declinação de apenas $4^{\circ}$; uma simples fita de cobre de 2 1/2 linhas de largura causou uma declinação ainda mais fraca.

2. Uma placa de antimônio entre as extremidades da espiral ou a fita de cobre simples comporta-se diferente. Se a espiral estiver em direção ao norte, as extremidades da mesma para o sul, assim a agulha no interior da espiral ficará mais a leste, quando a extremidade superior da mesma for comprimida sobre a placa de antimônio. O comportamento do antimônio, assim, é justamente oposto ao do bismuto. A declinação na conexão de cobre com antimônio era mais fraca do que a no circuito de bismuto com cobre, mas ainda significativamente. 
[268] 3. O terceiro metal, uma placa de zinco, agora conectado à espiral de cobre, mais uma vez demonstrou um comportamento diferente. $\mathrm{O}$ fechamento do círculo \{malha\} ocorreu aqui sem declinação, a agulha magnética manteve-se perfeitamente em repouso.

4. Da mesma maneira que foi feita pouca declinação como em uma placa de prata ou em um conjunto de cobre em vez do zinco. A agulha magnética se moveu um mínimo, da sua posição no meridiano magnético, e ainda menos do que se esses metais estão associados com zinco, do que quando aplicados individualmente.

5. Em todas estas pesquisas fechei o circuito colocando a placa metálica que seria investigada na extremidade inferior da espiral ou da simples fita, e pressionando para baixo a extremidade livre superior da placa com os dedos. Nas primeiras investigações, entretanto, questões poderiam surgir como se a mão não tomaria o lugar do condutor umedecido, e se o bismuto e o antimônio não dariam seus desvios opostos porque um deles, por razão da umidade da mão, tornar-se-ia com cobre $+E$, enquanto que o outro se torna $-E^{11}$.

A completa ausência de uma tensão magnética ao conectar o zinco à lâmina de cobre, onde, de acordo com este pressuposto uma tensão mais forte deveria ter ocorrido, já havia indicado algumas preocupações nesse sentido. Algumas experiências onde foram empregados condutores úmidos, mostraram ainda a certeza de que a umidade da mão, neste caso, não pode participar. Porque se a extremidade superior da espiral, por meio de uma placa de papelão umedecido com água, foi pressionada sobre a placa de bismuto e a declinação assim, não ocorreu; e se o papelão for umedecido com água e sal, a declinação oposta à que tinha surgido quando o toque com a mão ocorreu. Outros condutores úmidos mostram um comportamento similar.

6. Totalmente como previsto, uma vez que aqui temos que lidar somente com células galvânicas comuns, foi ao contrário do que ocorreu depois, quando a extremidade superior livre da fita de cobre foi pressionada contra a placa de bismuto ou de antimônio que estava abaixo, utilizando-se uma vareta de um outro metal qualquer, assim [269] ${ }^{12}$, mesmo se a extremidade superior da espiral, que foi colocada em contato com a placa de bismuto ou de antimônio for coberta com uma placa de vidro fina e seca, e esta for tocada com a mão durante algum tempo, de modo a manter o circuito fechado pelo mesmo tempo, são obtidas declinações mais fracas do que aquelas em que há o contato direto dos metais na formação do circuito.

Esta informação também foi refutada, já que provavelmente há uma eletricidade realizada no contato destes dois metais com a mão, através de um corpo seco, que poderia ser a causa da tensão magnética.

\footnotetext{
${ }^{11}$ Para visualizar melhor o procedimento realizado por Seebeck, construímos uma imagem. Ver anexo.

${ }^{12}$ Não conseguimos identificar o significado desta numeração incluída ao longo do parágrafo.
} 
7. A extremidade superior da espiral foi fixada sobre a placa de bismuto, e a extremidade inferior da mesma pressionada contra a superfície inferior do bismuto com a mão; agora a declinação fez o oposto do indicado no $§ 1$, onde foi fechado com a mão acima.

Se as duas extremidades da espiral forem ao mesmo tempo comprimidas em cima e em baixo, com os dedos sobre a placa de bismuto, assim nenhum desvio aparece na agulha magnética.

8. Em vez da espiral simples ou o arco de folha de cobre, outros metais agora têm sido aplicados, particularmente finos de 11/2 a 2 pés de comprimento e de 4 a 6 linhas de largura de fita de zinco, estanho, chumbo, prata e platina. O bismuto tem com cada um deles a mesma declinação como no encerramento com a fita de cobre, isto é, a Oeste, quando o arco com a bússola dentro do mesmo estava ao norte, e o bismuto, no Sul, e o circuito foi fechado no topo com a mão. $\mathrm{O}$ antimônio efetuou, com todas aquelas fitas de metal, a declinação oposta, ou seja, \{uma declinação\} leste no local especificado e \{a parte $\}$ superior $\{$ do circuito $\}$ fechada. Ele se comportou de forma semelhante entre as fitas de cobre. O cobre entre estas chapas de metal não mostrou nenhum efeito.

9. Dos outros metais, que tive a oportunidade de examinar, achei níquel, cobalto e urânio em conjunto com a espiral de folha de cobre, iguais ao bismuto; por outro lado, [270] ferro, aço, arsênio e telúrio iguais ao antimônio; aqueles ao sul, entre as extremidades da espiral deitada e fechada a partir de cima, oeste; estes efetuando declinações leste.

O cobre se comportou igual ao zinco, chumbo, estanho, mercúrio, prata, ouro, platina, paládio, cromo, latão. Nenhum deles forneceu, no fechamento com a espiral, uma declinação perceptível ${ }^{13}$.

10. Até mesmo alguns metais e minérios nobres, que Mr. Weiss teve a bondade de me comunicar do Real Gabinete de Minerais, foram examinados. Apenas uma parte do minério, do total entregue, foi possível de ser utilizada. Ambos os comportamentos serão especificados mais abaixo. Aqui vou apenas mencionar que, em conexão com a espiral de cobre, e, no fechamento substituindo o bismuto, agiram iguais: galena, pirita, calcopirita, arsênico, cupro-níquel, esmaltite branco; e ao antimônio se comportaram iguais: vidro cobre, bornite e pirrotite laminada.

11. Em todos estes experimentos a ação foi mais forte quando os metais e os minérios estavam imediatamente em contato com as mãos; e foi mais fraca quando o circuito estava fechado com uma fina chapa de algum corpo entre eles, (a qual, no entanto, se for não-metálica, não deve ser colocado entre a espiral e o metal ou minério que será investigado, mas sobre ambos), e todas as ações \{dos circuitos\} sobre a agulha magnética falhavam se as extremidades da espiral fossem pressionadas para baixo sobre a placa de metal com hastes de vidro, madeira ou metal com 2 pés de comprimento. Contudo, logo se observou um movimento da agulha

\footnotetext{
${ }^{13}$ N.A. - Os raros desses metais devo à gentileza do Sr. Bergemaiin, Frick, Goedeking e Hermbstüdt.
} 
magnética quando a mão foi colocada sobre a extremidade de baixo da haste metálica, perto do lugar em que ela fechava o circuito, e foi mantida por um tempo. A partir destas observações, sugere-se que o calor que é comunicado pelas mãos mais intensamente para um dos pontos de contato dos metais pode ser a causa do magnetismo nestes circuitos [271] com dois elementos. Por isso, era de se esperar que um grau mais elevado de temperatura do que aquele fornecido pela mão aos metais, provocaria uma maior tensão magnética. As investigações seguintes confirmaram isto.

12. Uma placa de bismuto foi trazida em contato com ambas as extremidades de uma espiral de cobre; uma placa fria de cobre foi colocada sob o circuito fechado e, acima dele, uma placa de cobre aquecida sobre uma lamparina. Um desvio \{na agulha\} ocorreu de uma só vez, e foi muito maior do que os obtidos na experiência anterior. A agulha magnética no interior da espiral foi defletida $50^{\circ}$ ou $60^{\circ}$ de um lado para outro e permaneceu parada em $17^{\circ}$. Em outros aspectos os desvios foram semelhantes aos experimentos anteriores, isto é, ele foi em direção ao oeste quando o aparelho foi arranjado conforme a Fig.1. Se a placa de cobre aquecida fosse colocada sobre o bismuto, o qual estava em contato com a fita de cobre, segue-se, quando todo o resto permaneceu inalterado, um desvio em direção leste que foi tão grande quanto o anterior em direção ao oeste.

13. Quando a placa de bismuto foi aquecida e imediatamente colocada na parte inferior da espiral, seguiu-se um desvio semelhante em direção ao leste quando a extremidade superior tocou o bismuto. Neste caso, a extremidade inferior da espiral foi aquecida, uma vez que permaneceu sempre em contato com a placa de bismuto; por outro lado, a extremidade superior, que só tocou a placa por um curto intervalo de tempo, estava mais fria, e de modo que o mesmo desvio deveria acontecer como no último experimento do parágrafo anterior.

Se ambas as extremidades da espiral foram trazidas em contato durante o mesmo intervalo de tempo com a placa de bismuto aquecida, nenhum desvio na agulha magnética foi mostrado.

14. Uma placa de antimônio na espiral, coberta com uma placa de cobre quente, causou também uma declinação mais forte do que antes, porém a direção da mesma, isto é, o oposto do que dera à luz o bismuto na mesma situação. A variação da agulha estava na posição indicada na Fig. 1 de $9^{\circ}$ a $10^{\circ}$ do leste da espiral.

[272] 15. Para as barras de bismuto e de antimônio de 5 polegadas a 2 pés de comprimento aquecidas em uma extremidade e conectadas imediatamente com a espiral ou um simples arco metálico, mostraram o mesmo comportamento como os discos de metal. A declinação dentro do arco é, quando a haste no sul e o arco está no norte, leste; no bismuto, se a extremidade abaixo quente; e oeste, se a extremidade quente está acima. Quando é antimônio, a declinação no primeiro caso é oeste e leste no segundo (Fig. 2 e 3, onde A antimônio, B bismuto e K significa o cobre). 
As declinações da agulha magnética acima e abaixo da malha fechada são sempre opostas aquelas dentro do círculo \{malha $\}$.

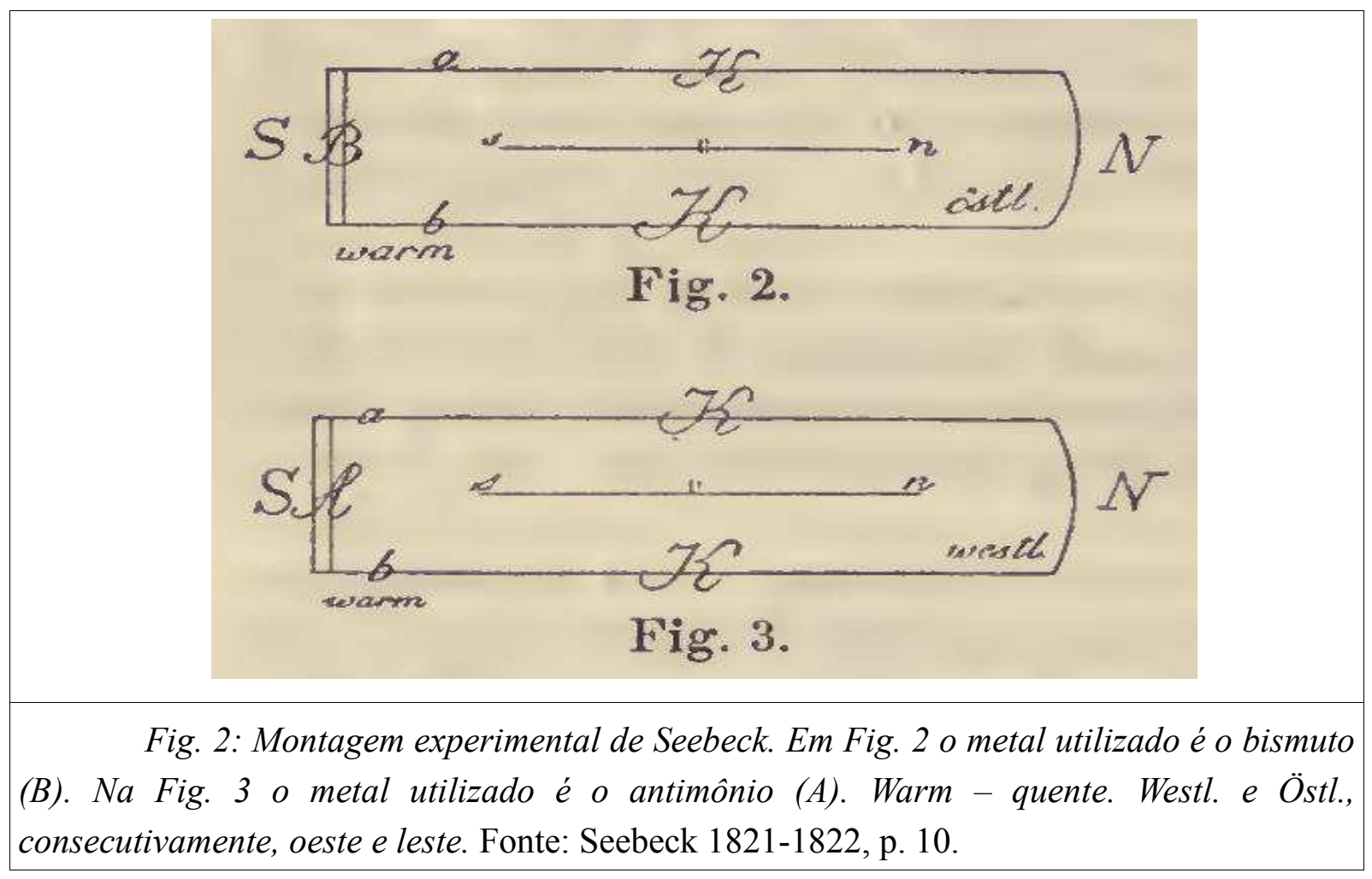

16. Se uma haste \{barra\} de bismuto ou antimônio aquecida exatamente no centro, encontra-se assim na aplicação das extremidades da espiral, para as extremidades das hastes, não há declinação. Se ambas as extremidades de uma barra de metal aquecidas ao mesmo tempo e fortemente iguais, ou seja, toda a barra for aquecida uniformemente, assim pode acontecer uma declinação, e ela até mesmo pode faltar completamente. O sucesso depende mesmo de, se as duas extremidades da espiral estão flutuando livremente, quando fechadas, ou se elas estão em contato com um outro corpo, e com qual \{corpo\}. Se a base $\{$ calço\}, em que uma das extremidades da espiral situa-se, é um mau condutor de calor, como por exemplo papelão ou madeira, assim esta pode acabar, quando ela está em contato com a barra quente, comportando-se como um aquecedor, e deve então acontecer uma declinação. Porém, se a base é de um bom condutor de calor, por exemplo, metal ou pedra, assim a sua declinação pode ser oposta, pois o arrefecimento da barra quente aqui é feito mais rápido do que na outra extremidade apenas em contato com o arco metálico. Se ambas as extremidades igualmente quentes da barra de metal forem conectadas simultaneamente a ambas as extremidades da espiral, assim feito, aqui também não há nenhum desvio da agulha magnética.

17. Igualmente se comportaram com o mesmo método outros metais citados em $\S 8 \mathrm{e}$ $\S 9$, mesmo os que ali ainda designados ineficazes [273]. Todos adquiriram, ligados em pares 
uns aos outros, aumentando a temperatura de um dos pontos de contato, uma polarização magnética; ambos os pontos de contato a mesma temperatura nenhuma \{polarização magnética\}. De fato, aparentemente alguns metais homogêneos apresentam o mesmo comportamento.

18. De todos esses experimentos podemos concluir que a primeira e mais importante condição para o aparecimento do magnetismo livre nesse circuito metálico é a diferença de temperatura nos pontos de contato dos dois elementos.

Sem dúvidas o magnetismo também será provocado se ambos os pontos de contato dos metais ou minérios são aquecidos ao mesmo tempo e a um mesmo grau; não haverá nenhuma ação na agulha magnética, no entanto, neste caso, porque através deste procedimento uma dupla e oposta polarização magnética será provocada no circuito, e porque esta é em toda parte de igual força. Aquecendo o ponto de contato superior (Fig. 2) temos a condição para um desvio a oeste, e aquecendo o ponto de contato inferior temos um desvio para o sentido leste. Estes se mantêm em equilíbrio e a agulha deve, portanto, permanecer em repouso.

O magnetismo deve ser provocado pelo simples contato de metade dos circuitos uns com os outros sem nenhuma mudança de temperatura, mas ele permanece latente, porque as ações dos dois metais em cada um dos outros são de força igual em ambos os pontos de contato e a polarização magnética provocada por eles têm direções opostas.

19. O resfriamento artificial de um dos dois pontos de contato irá produzir uma tensão magnética nestes circuitos metálicos de dois elementos, tão bem como faz o aquecimento, por quebrar o equilíbrio magnético. Uma haste de bismuto de 15 polegadas de comprimento, a qual, dentro de um tudo de vidro, em uma mistura de gelo e sal foi refrigerada, enquanto a outra extremidade praticamente manteve a sua temperatura anterior, comportou-se em ligação com a espiral de cobre da mesma maneira que se a diferença da temperatura de ambas as extremidades da haste poderia ter sido causada por um aquecimento da mesma. Se a extremidade fria estava acima, então a declinação era leste (como na Fig. 2), se ela estava abaixo a declinação era oeste. O movimento [274] da agulha foi de $30^{\circ}$ no primeiro fechamento. Uma haste de antimônio tratada da mesma forma, deu, se a extremidade fria estava acima, uma declinação ocidental \{oeste\} (como na Fig. 3), contudo uma mais fraca que a do bismuto ${ }^{14}$.

\footnotetext{
${ }^{14}$ N.A. - Mais tarde eu empreguei em conjunto com o Sr. H. Rose algumas experiências com graus mais elevados de frio. Um anel consistindo de metade de antimônio com $1 / 2$ polegada de espessura e metade de uma fina folha de cobre com $1 / 2$ polegada de largura, foi colocado em uma mistura de duas partes de neve e três partes finas de pó clorídrico de cal. Foi realizada uma declinação dormente da agulha magnética dentro do círculo de $8^{\circ}$ leste, quando o antimônio no sul e o cobre estava no norte, e a temperatura da mistura fria causando nos pontos inferiores de contato $-38^{\circ}$ R., e a da sala $-6^{\circ}$, respectivamente. Um quadro quadrangular de bismuto e antimônio, que foram conectados um ao outro por fusão, mostrou-se ainda eficaz. A declinação da agulha magnética no interior do mesmo, aumentou para $35^{\circ}$ oeste e manteve-se quase uma meia hora de forma que, o bismuto no sul, o antimônio estava no norte, e a temperatura nos pontos de contato inferiores dos metais $-43^{\circ}$ e acima estava $-6^{\circ} \mathrm{R}$ \{temperatura da sala . Ambas as cadeias de duas camadas se tornaram igualmente assim polar, como se seus pontos de contato de cima tivessem sido aquecidos.
} 
22. Se uma folha de papel ou de baudruche ${ }^{15}$ for empurrado entre ambos os metais na parte fria dos pontos de contato, por exemplo, entre o antimônio e o cobre, em $a$ Fig. 4, enquanto o ponto de contato $b$ é aquecido com uma lamparina de álcool, assim não se mostra nenhum traço de efeito sobre a agulha magnética. Uma sólida cobertura dos metais com oxido nos pontos de contato também cancela o efeito; um menor traço de óxido enfraquece-o somente. Localizando-se em $a$, na Fig. 4, um disco de papel molhado com água, assim a agulha magnética permanece completamente em repouso, por mais que a temperatura de $b$ seja elevada; porém, uma declinação é criada imediatamente quando uma terceira haste de metal está \{aplicada\} em $c d$. Se o disco de papel ou papelão em $a$ [276] \{forem\} molhados com ácidos ou álcalis cáusticos, então em vez disso encontra-se de fato uma declinação da agulha magnética, porque o circuito \{cadeia\} agora atua como uma \{bateria\} galvânica, porém essas levam, na atuação química da pequena superfície, à fracas declinações, provavelmente alteradas pelo aquecimento dos pontos de contato $b$, uma vez que o magnetismo daqueles metais é forte em contato imediato em $a$, ou na aplicação de uma terceira fita metálica em $c d$. O contato imediato dos metais é, portanto, uma segunda condição essencial para a polarização magnética dos mesmos por diferença de temperatura.

Fig. 3: Representação da configuração experimental do $\S 22$ de Seebeck. Na figura,
K significa cobre e A antimônio. Fonte: Seebeck, 1821-1822, p. 13 .

23. Quanto mais perfeita é a ligação de ambos os metais, mais forte é seu magnetismo. Aparatos, em que hastes ou semicírculos de antimônio e bismuto são conectados com a fita de

\begin{abstract}
N.T. - Seebeck não deixa claro qual é a escala termométrica que utilizou em seus trabalhos, isto porque ele faz uma abreviação da mesma apenas com a letra ' $R$ '. Temos conhecimento de três escalas as quais suas abreviaturas começam com a letra R, são estas: a) Roemer (Rø), criada por Ole Roemer (1644-1710); Réaumur (Ré) criada por René-Antonie Ferchault de Réaumur (1683-1757); e c) Rankine (Ra) criada por William John Macquorn Rankine (1820-1872). Dentre estas, logicamente, excluímos a Rankine, visto que o criador desta escala nasceu em 1820 e os trabalhos de Seebeck são de 1821 sendo impossível utilizá-la, pois só seria elaborada anos mais tarde. Restamnos duas possíveis escalas termométricas que ele pode ter utilizado. Segundo Pires et al (2006) existia uma grande quantidade de escalas termométricas que surgiram no século XVIII, porém três obtiveram maior disseminação e uso no meio científico nos séculos XIX e XX. Estas escalas eram Réaumur, Fahrenheit ( ${ }^{\circ} \mathrm{F}$, Daniel Gabriel Fahrenheit, 1686-1736) e Celsius ( ${ }^{\circ} \mathrm{C}$, Anders Celsius 1701-1744). Embora a evidência favoreça ao fato de que, provavelmente, a escala utilizada por Seebeck tenha sido Réaumur ao invés de Roemer não nos comprometeremos em assinalar uma destas em particular. Para mais detalhes históricos sobre as escalas termométricas ver Pires et al. (2006).
\end{abstract}

${ }^{15}$ N.T. - Baudruche é uma película extraída do intestino de animais, utilizada para fazer balões. 
folha de cobre (Fig. 5, 6, 7, 8, 9) ${ }^{16}$, atingem pelo mesmo aumento ou diminuição da temperatura uma maior polaridade magnética, do que esse em que os metais se tocam apenas externamente.

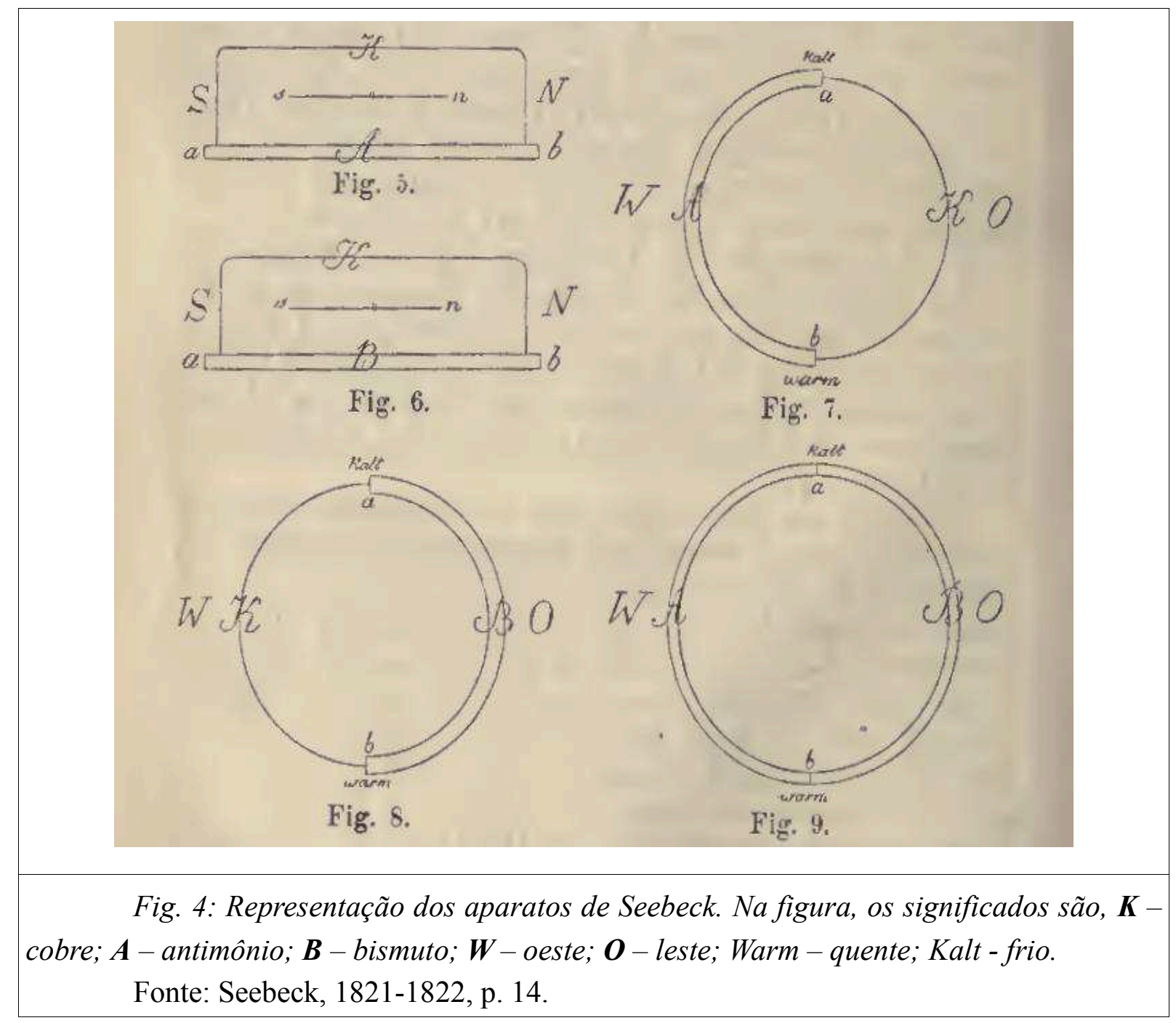

24. Esses aparatos também são altamente adequados, porque eles estão mais protegidos contra a ação oxidante do ar, do $§ 15$ ao $\$ 20$ apareceram alterações nas polarizações magnéticas dos metais, no aquecimento ou resfriamento unilateral ou mútuo dos pontos de contato, - para mostrar o aumento, enfraquecimento, anulação e a inversão da polaridade. Se, por exemplo, uma lamparina é colocada abaixo do antimônio associado com o cobre (Fig. 5) em $a$, acontece uma declinação leste do polo $\mathrm{N}$ da agulha magnética entre $\mathrm{AK}$; está a lamparina abaixo de $b$ então a declinação é oeste. Se duas lamparinas com chamas igualmente grandes, e em iguais intervalos \{de distância\} dos metais, uma abaixo de $a$, outra embaixo de $b$, então a agulha permanece parada no meridiano magnético, pois em seguida a temperatura em $a$ e $b$ aumenta uniformemente; porém, uma declinação da agulha ocorre imediatamente quando uma das chamas

\footnotetext{
${ }^{16}$ N.T. - Notações nas figuras (7, 8 e 9): warm-quente; kalt-frio; $N$-norte; $S$-sul; $W$-oeste; $O$-leste.
} 
aumenta ou diminui, ou é movida de seu lugar. Se alguém aquece a haste de antimônio ou a fita de cobre [277] no centro, assim não se percebe nenhuma declinação, porém ela mostra-se imediatamente, conforme aproxima-se a lamparina apenas um pouco da extremidade $a$ ou $b$, mas ela é em seguida sempre mais fraca, do que quando o aquecimento acontece nos pontos de contato dos próprios metais; e assim por diante.

Se a bussola abaixo de $A$ ou sobre $K$, então a declinação no aquecimento de $a$ é oeste e no $b$ leste; porém elas são aqui, a mesma distância da agulha magnética dos metais, sempre mais fracas do que entre $A K$.

\section{Considerações finais}

Com os estudos pode-se concluir que o fenômeno observado por Seebeck, não se tratava de termoeletricidade, mas estavam se referindo a um fenômeno puramente magnético, e, como sugerido por ele, uma polarização magnética, a qual se manifestaria no circuito quando se perturbava a temperatura dos metais distintos que o compunham. Se prestarmos atenção no título do seu trabalho percebemos que ele não é sugestivo de termoeletricidade, mas destaca bem uma tendência a estudos magnéticos.

$\mathrm{Na}$ concepção dos conceitos atuais certamente sabemos que os efeitos magnéticos provocados nos circuitos experimentais de Seebeck são devidos a uma corrente elétrica que é produzida quando fornecemos calor a uma das extremidades de um circuito bimetálico. Entretanto o que Seebeck investigou foram as causas desta corrente termoelétrica - a chamada polarização magnética.

A análise realizada mostrou diferentes nuances do trabalho científico durante o final do século XVIII e início do século XIX, como a busca pela interação das forças da natureza, a influência da Naturphilosophie e o sem número de experimentos realizados e equipamentos inventados a partir dos estudos de eletricidade e magnetismo. O presente estudo de caso demonstra ainda uma situação muito comum no Ensino de Ciências, que a interpretação de resultados históricos sob a perspectiva atual, como o conhecido "efeito Seebeck", que não tem nada a ver com o trabalho de Seebeck.

\section{Agradecimentos}

Os autores agradecem o apoio financeiro do Conselho Nacional de Desenvolvimento Científico e Tecnológico (CNPq) através do Edital Universal Proc. 474924/2012-2 e de bolsa de Iniciação Científica.

\section{Referências}

ANATYCHUK, L. I. On the discovery of thermoelectricity by Volta. Journal of Thermoelectricity, n. 2, p. 5-10, 2004. 
CANEVA, K. L. Physics and Naturphilosophie: A reconnaissance. History of science, v. 35, n. 1 , p. $35-106,1997$

CANEVA, K. L. The form and function of scientific discoveries. Washington, DC: Smithsonian Institution Libraries, 2001. p. 5-10.

COMASCO, P. Collezione dell'opere del cavaliere Conte Alessandro Volta. Tomo II parte I.Firenze. Nella stamperia di Guglielmo Piatti, 1816.

MAGIE, W. F. Seebeck. In: Source Book in Physics. New York and London. McGraw-Hill Book Company, Inc. First Edition - Fifth Impression, 1935. p. 461-464.

MAGALHÃES, G. Ciência e Filosofia da natureza no século XIX: Eletromagnetismo, Evolução e Ideias. In: SEMINÁRIO DE HISTÓRIA DA CIÊNCIA E DA TÉCNICA, 10, 2005. Anais... p. 1-38.

MARTINS, R. A. Alessandro Volta e a invenção da pilha: dificuldades no estabelecimento da identidade entre o galvanismo e a eletricidade. Acta Scientiarum. Technology, v. 21, p. 823835, 2008.

MARTINS, R. A. Ørsted e a descoberta do eletromagnetismo. Cadernos de História e Filosofia da Ciência, v. 10, p. 89-114, 1986.

OERSTED, H. C. Recherches sur l'identité des Forces chimiques et eléctriques. Tradução: M. Marcel de Serres. Paris: J. G. Dentu, Imprimieur-Libraire, 1813.

PASTORINO, G. Alessandro Volta and his role in thermoelectricity. Journal of Thermoelectricity, v. 1, p. 7-10, 2009.

PIRES, D. P. L.; AFONSO, J. C.; CHAVES, F. A. B. A termometria nos séculos XIX e XX. Revista Brasileira de Ensino de Física, v. 28, n. 1, p. 101-114, 2006.

ROGALSKI, A. Infrared detectors: an overview. Infrared Physics \& Technology, v. 43, p. 187-210, 2002.

SEEBECK, T. J. Magnetische polarisation der Metalle und Erze durch Temperatur -Differenz (1821-1823). Leipzig: Verlag von Wilhelm Engelmann, 1895.

VELMRE, E. Thomas Johann Seebeck (1770-1831). Proc. Estonian Acad. Sci. Eng., v. 13, n. 4, p. 276-282, 2007. 


\section{Anexo}

Ilustração do procedimento adotado por Seebeck no experimento descrito no $§ 5$.

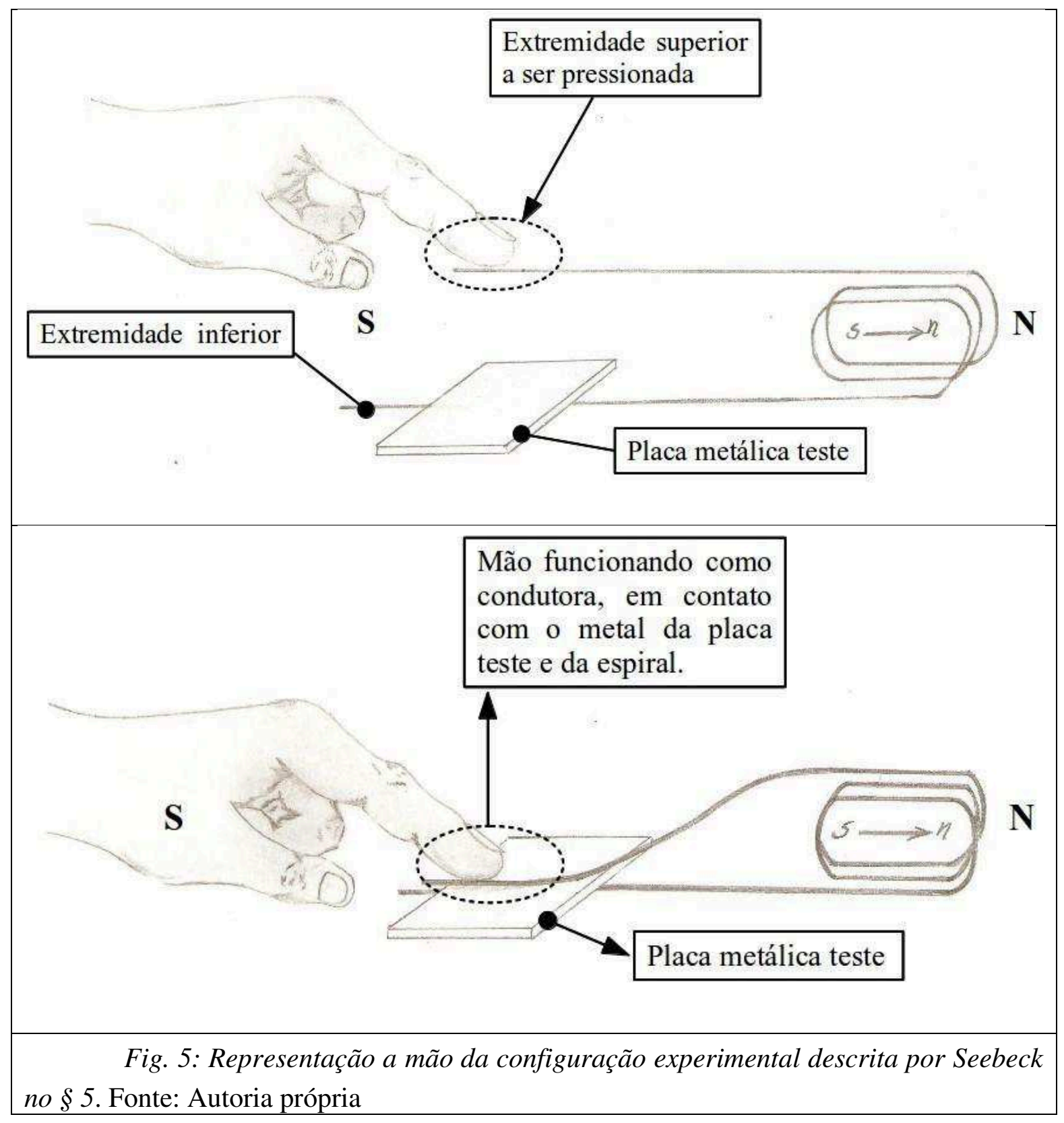

